\title{
Isolation and Molecular Characterization of Chromium Resistant Fungi Having Competence to Degrade Anthracene from Industrial Effluent of South Gujarat
}

\author{
Patel Shriram ${ }^{1}$, Darji Nikita ${ }^{1}$, Kunjadia Prashant $^{2}$, and Kunjadia Anju ${ }^{1 *}$ \\ ${ }^{1}$ Ashok and Rita Patel Institute of Integrated Study and Research in Biotechnology and Allied Sciences, Anand, \\ Gujarat (INDIA) - 388121. \\ ${ }^{2}$ Department Pharmaceutical Sciences, Sardar Patel University, Gujarat (INDIA).
}

\begin{abstract}
Fungi being robust organism makes significant contribution in natural remediation of heavy metals and xenobiotic compound. Out of the thirty three different fungi isolated twenty two isolates were found to be chromium resistant. Fungus belonging to genera Penicillium and Trichoderma sp. were highly resistant to chromium up to 2000-2500ppm. Biosorption studies of chromium evaluated using live biomass of fungi shows maximum biosorption of the $\mathrm{Cr}^{6+}$ i.e. $74 \%$ of $1000 \mathrm{ppm} \mathrm{Cr}^{6+}$ after 14 days. Degradation of anthracene with four different fungus isolates were studied and of them Penicilliumsp., Tichoderma sp. and Penicilliundecumbenshave confirmed their ability to degrade anthracene in minimal media. All the isolates were identified based on $18 S$ rDNA gene sequencing and sequence were submitted to GenBank under accession no. KF284156-61 for Aspergillusterreus, Penicillium Sp., Penicilliumdecumbens, Trichodermaamazonicum, Hypocreaatroviridis and Trichoderma Sp. respectively. Phylogenetic study with some Cr resistant and/or PAHs degrading fungi was also carried out by using MEGA5. In all Penicilliundecumbenshas proven to be potentially useful strain and can be used for bioremediation of industrial effluent containing chromium and anthracene.

Key words: Bioremediation, Heavy metal, Chromium, Biosorption, Anthracene, MEGA5.
\end{abstract}

\section{Introduction:}

India has shown significant progress in the area of industrial development during past few decades but at the same time it has also invited major problem regarding the environmental pollution. Indiscriminate discharge of toxic heavy metals and PAH (Poly Aromatic Hydrocarbon) through effluents from a wide range of industries into water bodies have polluted these resources and causes lethal effects on flora and fauna [1-5]. Contamination of sediments and natural aquatic receptors with heavy metals is a major environmental problem all over the world[6]. All metals at high concentrations are potentially poisonous, whether or not they are biologically crucial at more moderate levels[7]. Chromium (Cr) is a highly toxic non-essential metal which is used on a large scale in many different industries. At many industrial sites, leaching and seepage of hexavalent chromium from the soil into the ground water account for considerable health hazard. Furthermore Polycyclic Aromatic Hydrocarbons (PAHs) are omnipresent environmental pollutants that is present in large quantity together with heavy metals and pose health problems linked to genotoxicity, carcinogenicity and allergenicity. As PAHs are genotoxic and carcinogenic, they represent a considerable environmental concern[8-11].

Bioremediation is a pollution control technology that uses biological systems to catalyse the degradation or transformation of various polluted chemicals to less harmful intermediates. Fungi have developed exceptional bioremediation machinery that is well known to deteriorate wide range of materials and compounds, processes known as mycodeterioration.[12]. As fungal biomass possess high percentage of cell wall material, it has been found effective in removal of heavy metals from industrial effluent due to excellent metal binding efficiency. So far many work on either biosorption of heavy metals[13-17] and degradation of PAHs or xenobiotic compounds[18-20] by filamentous fungi have been reported. Some researchers have focused on especially removal of hexavalent chromium[21-23]. But to our best knowledge none of the work on simultaneous isolation of $\mathrm{Cr}^{+6}$ resistant fungi having potential to degrade anthracene has been carried out. As industrial effluent contains mix consortia of heavy metals and PAHs and other pollutants it is of advantageous to study these characteristics mutually. Thus the present study was started with aims to isolate $\mathrm{Cr}^{+6}$ resistant fungi having potential to degrade anthracene, a three ring containing PAH.

\section{Study areas and samples collection}

\section{Materials and Methods}

Effluent water and deposited mud was collected from 3 different sites of Amlakhadi near Ankleshwar, Gujarat. And composite sample was formed by combining mud and water and mixing thoroughly before analysis. 


\section{Chemical analysis of sample}

The concentration of heavy metals that were present in the sample was analyzed using ICP-OES (Inductive Coupled Plasma-Optical Emission Spectrophotometer) analysis subsequent to acid digestion of the sample. Compound other than heavy metal that is Xenobiotic compound were extracted with hexane and detected by GC-MS analysis.

\section{Isolation of Chromium resistant fungi}

Effluent sample was diluted to 10-1, 10-2 and 200 $\mu$ l from each dilution was spread on PDA plates supplemented with $100 \mathrm{ppm} \mathrm{Cr}^{6+}$. Tetracycline $(30 \mathrm{mg} / \mathrm{L})$ was added to PDA to evade any other bacterial contamination. Plates were incubated at $28^{\circ}{ }^{\circ}$ for 3-7 days and colonies which were grown were purified on PDA plates for further analysis.

\section{Determination of MIC of Chromium}

MIC of the chromium for the isolates were determined by inoculating fungal spore suspension in $25 \mathrm{ml}$ of PDB supplemented with chromium at different concentrations ranging from 200-1000ppm. The tubes were incubated at $28^{\circ}$ for 7 days. MIC was considered when isolates failed to grow at particular concentration. Isolates which showed growth at $1000 \mathrm{ppm}$ was further checked at higher concentration of chromium until growth disappear.

\section{Biosorption of Chromium}

Biosorption of chromium was performed using live biomass of seven fungi which were showing maximum and minimum MIC for $\mathrm{Cr}^{6+}$. Initially all the fungi were grown in 50ml of PDB medium for 7 days at $28^{\circ} \mathrm{C}$. Biomass was filtered and partially dried on sterile paper in laminar air flow. $1 \mathrm{gm}$ of partially dried biomass was weighted and transferred to $50 \mathrm{ml} \mathrm{PDB}$ amended with $1000 \mathrm{ppm}$ of chromium in the form of $\mathrm{K}_{2} \mathrm{Cr}_{2} \mathrm{O}_{7}$. Then flasks were incubated in shaking condition at $28^{\circ}$. For each 7th and14th day, $1 \mathrm{ml}$ of medium from each flask was taken aseptically and chromium was estimated using DPC method[24].

\section{Anthracene degradation}

The fungi showing maximum $\mathrm{Cr}^{6+}$ biosorption were studied for its efficiency to degrade anthracene. A spore suspension was prepared by adding 5 blocks of $8 \mathrm{~mm}$ diameter from PDA plates previously grown at $28^{\circ} \mathrm{C}$ for 14 days. $500 \mu \mathrm{l}$ of this spore suspension was added to each flask containing $70 \mathrm{ml}$ of minimal media $\left[\left(\mathrm{NH}_{4}\right)_{2} \mathrm{HPO}_{4}-0.50 \mathrm{gm} / \mathrm{L}, \mathrm{KH}_{2} \mathrm{PO}_{4}-0.80 \mathrm{gm} / \mathrm{L}, \mathrm{K}_{2} \mathrm{HPO}_{4}-0.30 \mathrm{gm} / \mathrm{L}, \mathrm{MgSO}_{4 \cdot 7} \mathrm{H}_{2} \mathrm{O}-0.30 \mathrm{gm} / \mathrm{L}, \mathrm{CaCl}_{2 \cdot 2} \mathrm{H}_{2} \mathrm{O}-\right.$ $0.045 \mathrm{gm} / \mathrm{L}, \mathrm{ZnSO}_{4.6} \mathrm{H}_{2} \mathrm{O}-0.004 \mathrm{gm} / \mathrm{L}$, Yeast extract $-0.4 \mathrm{gm} / \mathrm{L}$, Thiamine $\left.-2 \mathrm{mg} / \mathrm{L}\right]$ with $50 \mathrm{ppm}$ anthracene and incubated at $125 \mathrm{rpm}$, at $28^{\circ} \mathrm{C}$ for 14 days. After 14 days each samples were extracted with $20 \mathrm{ml}$ of hexane and extract was concentrated to $1 \mathrm{ml}$ by evaporating extracted sample in water bath and GC-MS analysis was done.

\section{Molecular characterization of fungal genomic DNA}

Genomic DNA was isolated by using standard protocol[25] 18S rRNA gene was amplified by using the universal primers, 18SF2 (5'-AGGGTTCGATTCCGGAGA-3') and 18SR2 (5'TTGGCAAATGCTTTCGC-3'). The PCR reaction mixture $(25 \mu \mathrm{l})$ contained $2.5 \mu \mathrm{lTaqA}$ Buffer (10X), 2.5 $\mu \mathrm{ldNTPs}$ Mix (2.5mM each), $1.0 \mu \mathrm{l}$ of each forward and reverse primer $(10 \mu \mathrm{M}), 1.0 \mu \mathrm{l}$ Genomic DNA (50$70 \mathrm{ng} / \mu \mathrm{l}), 0.2 \mu \mathrm{lTaq}$ polymerase $(5 \mathrm{U} / \mu \mathrm{l})$ and make up with MiliQ water to $25 \mu \mathrm{l}$. Amplification was carried out in a thermocycler (NYX-TECHNIK, T062911-007, USA) with cycling condition $94^{\circ} \mathrm{C}$ for 5 min, followed by 40 cycles of $94^{\circ} \mathrm{C}$ for $1 \mathrm{~min}, 58^{\circ} \mathrm{C}$ for $1 \mathrm{~min}, 72^{\circ} \mathrm{C}$ for $1 \mathrm{~min}$ and final extension at $72^{\circ} \mathrm{C}$ for $5 \mathrm{~min}$. PCR product obtained was sent for sequencing to Eurofin Genomics Pvt. Ltd. Bangalore, India. After sequencing, the partial sequence was then subjected to a BLAST search with nr database at NCBI to identify the fungi. Phylogenetic analysis of the sequence was performed with MEGA5 program[26]. The phylogenetic tree was constructed with 22 fungi having potential to remove $\mathrm{Cr}^{+6}$ and/or degrade xenobiotic compounds using the neighbor-joining method.

\section{Results and Discussion}

\section{Detection of heavy metals and Xenobiotic compound present in the sample}

Ankleshwar industrial estate (Gujarat, India) consists of nearly 3000 industrialized units. Majority of the industries manufacture chemicals, dyes, paints, fertilizers, pharmaceuticals, pesticides and other xenobiotic compounds. The treated and untreated contaminated effluents from various industries of Ankleshwar industrial estate are finally released in Amlakhadi canal. Amlakhadi canal further ends up in Narmada estuary that enters the Arabian Sea, Gujarat. Kathuria (2007) found that this canal is highly polluted with different toxic metals such as chromium, cadmium, mercury, zinc and others. Beside these, canal is also contaminated with various organic compounds such as chlorinated benzene, phenolics, petroleum hydrocarbons, polychlorinated biphenyl 
and others. Many of these pollutants (PAHs) adsorb on to particulate matter due to their hydrophobic nature and settle down as sediment. Therefore, sediment of this canal has become sinking of recalcitrant compounds and poses a major threat to the ecosystem. Hence, Amlakhadi canal sediment was selected for isolation of metal resistant and PAHs degrading fungi.

Results of ICP-OES analysis shows that different heavy metals were present in range from $0.0042 \mathrm{ppm}$ - $28.426 \mathrm{ppm}$ in the sample (Table 1). Magnesium (Mg) - $28.426 \mathrm{ppm}$ was found to be most abundant metal followed by Manganese (Mn) - $1.3824 \mathrm{ppm}$ and Iron (Fe) - $1.3824 \mathrm{ppm}$ then rest of metals. Moreover Chromium $(0.2746 \mathrm{ppm})$ is present in effluent above the permissive limit which is mentioned in the guideline of Indian Standard Specification for discharge of environmental pollutants. GC-MS analysis followed by peak identification revealed that industrial effluent contained different phenolic derivatives and different xenobiotic derivatives like 1 - benzopyran, anthracene, 9,10, dihydro anthracene 1,2, dihydro etc. This means that the water sample is contaminated with xenobiotic recalcitrant compounds. Figure 1 shows mass spectra of different compounds present in effluent sample.

Table 1: Heavy Metal Analysis of Sample by ICP-OES.

(BDL=Below Detection Limit)

\begin{tabular}{|c|c|c|c|}
\hline Elements & $\begin{array}{l}\text { Wavelengths } \\
\text { (nm) }\end{array}$ & $\begin{array}{c}\text { Instrument detection limit } \\
\text { ppm (mg/l) }\end{array}$ & $\begin{array}{c}\text { Sample results ppm } \\
(\mathrm{mg} / \mathrm{l})\end{array}$ \\
\hline Iron (Fe) & 238.204 & 0.0014 & 1.3824 \\
\hline Copper (Cu) & 327.393 & 0.0097 & 0.9431 \\
\hline Nickel (Ni) & 231.604 & 0.0150 & 0.2106 \\
\hline Chromium (Cr) & 231.160 & 0.0071 & 0.2746 \\
\hline Manganese (Mn) & 257.610 & 0.0014 & 1.3824 \\
\hline Magnesium (Mg) & 285.213 & 0.0016 & 28.426 \\
\hline Mercury (Hg) & 253.652 & 0.0610 & BDL \\
\hline Cadmium (Cd) & 228.802 & 0.0027 & 0.0042 \\
\hline Lead (Pb) & 220.353 & 0.0420 & 0.2364 \\
\hline Zinc (Zn) & 206.200 & 0.0059 & 1.0566 \\
\hline
\end{tabular}

Figure 1: GC-MS Report of Industrial Effluent.

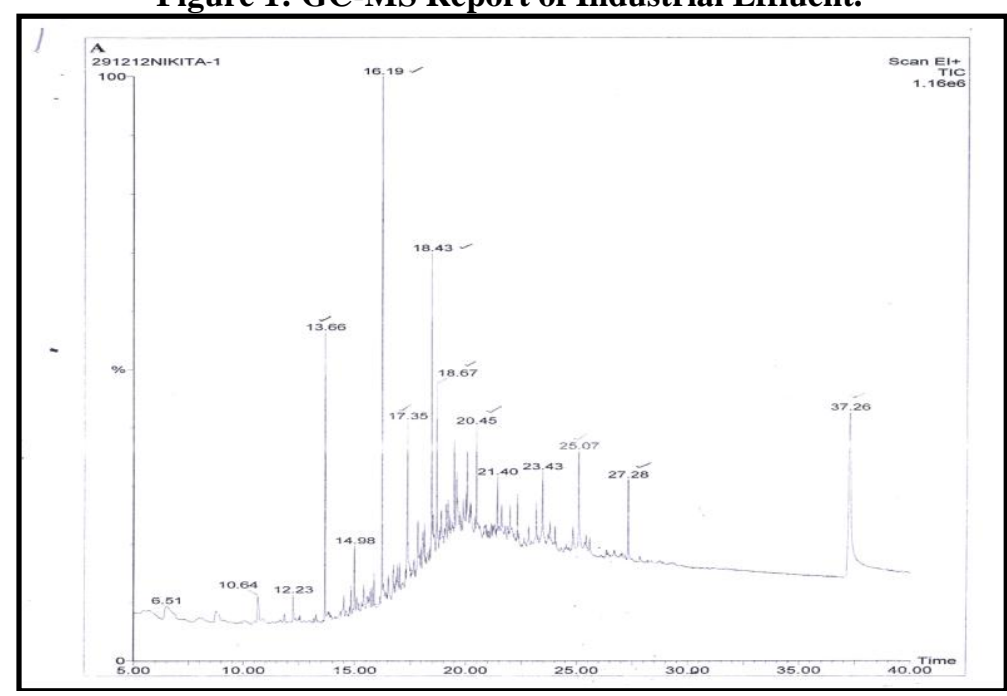

\section{Determination of MIC and Biosorption of Chromium}

Long time exposure of fungi to heavy metals can lead to physiological adaptation to that condition[28], and such changes may results in increased metal tolerance and biosorption capacity. In the present study, it seems that continuous exposure of fungi to chromium deposited in wastewater might have exerted selection pressure on to fungal population resulting in the development of chromium resistant strains. All over 22 different isolates showed chromium resistant capacity with varying level as evident from the MIC value in Table 2. Data suggest that isolates were resistant to heavy metal ranging from 400-2500ppm. This indicates that different isolates have different tolerance capacity to chromium. Isolates having MIC value more than 2000ppm were studied for its biosorption competence to remove chromium form liquid medium. Isolate SP-9 showed maximum chromium removal capacity i.e. $62 \%$ and $78 \%$ on 7 th and 14 th day of incubation respectively, followed by SP-6 i.e. $62 \%$ and 74\%. In contrast isolate SP-2 and SP-10 showed less sorption of chromium in same condition. Our results are comparable with those obtained by Tsubasa et al. (2008), Zafar at al. (2007), and Say et al. (2004). Tsubasa et al. (2008) reported biosorption of Cr (VI) up to 35\% and 93\% respectively by Aspergillius sp. and Penicilliumsp[29]. Some Penicillium sp. Aspergillius sp. and Trichoderma sp. were also 
reported to adsorb chromium[30]. Penicilliumpurpurogenum has the capacity to absorb $36.5 \mathrm{mg}$ of $\mathrm{Cr}$ (VI) per gms of fungal biomass[31]. From the data it can be concluded that metal tolerance and metal uptake by living organism is based on the same mechanism because isolate with most MIC showed high biosorption potential (SP-9 \& 6) and isolate with least MIC showed less biosorption potential (SP-2 \& 10). Figure 2 shows Chromium removal efficiency of seven different isolates.

Table 2: MIC Values of Chromium.

\begin{tabular}{lllll}
\hline Name of Isolates & MIC values (ppm) & & Name of Isolates & MIC values (ppm) \\
\cline { 1 - 2 } SP-1 & 400 & & SP-12 & 600 \\
\hline SP-2 & 600 & & SP-13 & 2100 \\
\hline SP-3 & 400 & & SP-14 & 2200 \\
\hline SP-4 & 700 & SP-16 & 2100 \\
\hline SP-5 & 400 & SP-17 & 2000 \\
\hline SP-6 & 2200 & SP-18 & 2100 \\
\hline SP-7 & 400 & SP-20 & 1600 \\
\hline SP-8 & 600 & SP-21 & 1700 \\
\hline SP-9 & 2500 & SP-22 & 2000 \\
\hline SP-10 & 500 & & 2200 \\
\hline SP-11 & 500 &
\end{tabular}

Figure 2: Chromium Removal Efficiency of Different Isolates.

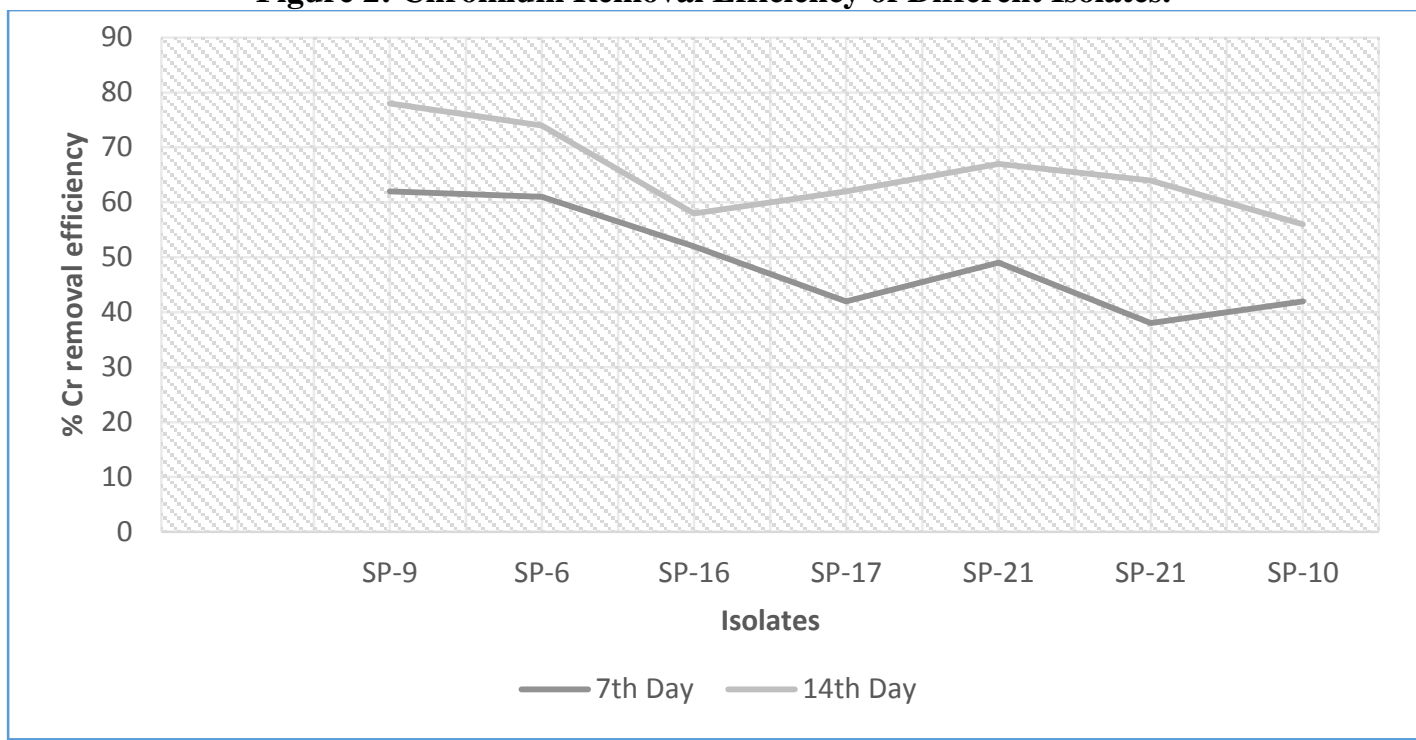

Anthracene degradation capacity

GC analysis of the extracted sample SP-10 (Figure 3) and SP-16 (Figure 4) shows that no peaks were observed for anthracene, so it can be concluded that isolates SP-10 and SP-16 has 100\% anthracene removal efficiency after 14 days of incubation. Here fungi may have utilized anthracene as a source of carbon. GC-MS analysis of the sample SP-6 showed less anthracene degrading efficiency i.e. 10\% (Figure 5). While SP-9 did not shows any anthracene degradation efficiency (Figure 6). Our results were comparable with data obtained by Vyas et al. (1994) and Yi-Rui Wu et al. (2010) for degradation of anthracene. Vyas et al. (1994) reported anthracene degradation of approximately $60 \%$ by selected white rot fungi in 21 days[32]. While Yi-Rui Wu et al. (2010) reported $40 \%$ anthracene degradation of the added amount $(50 \mathrm{mg} / \mathrm{L})$ by 40 days of incubation[33]. 


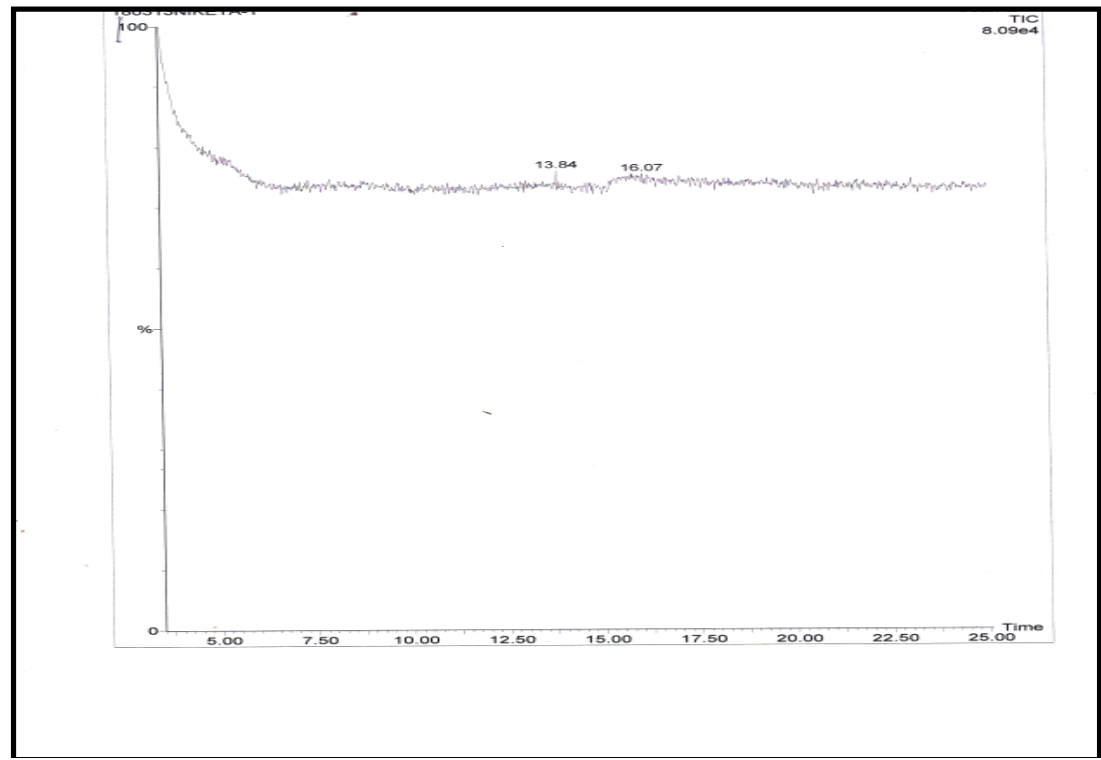

Figure 3: GC Analysis of SP-10.

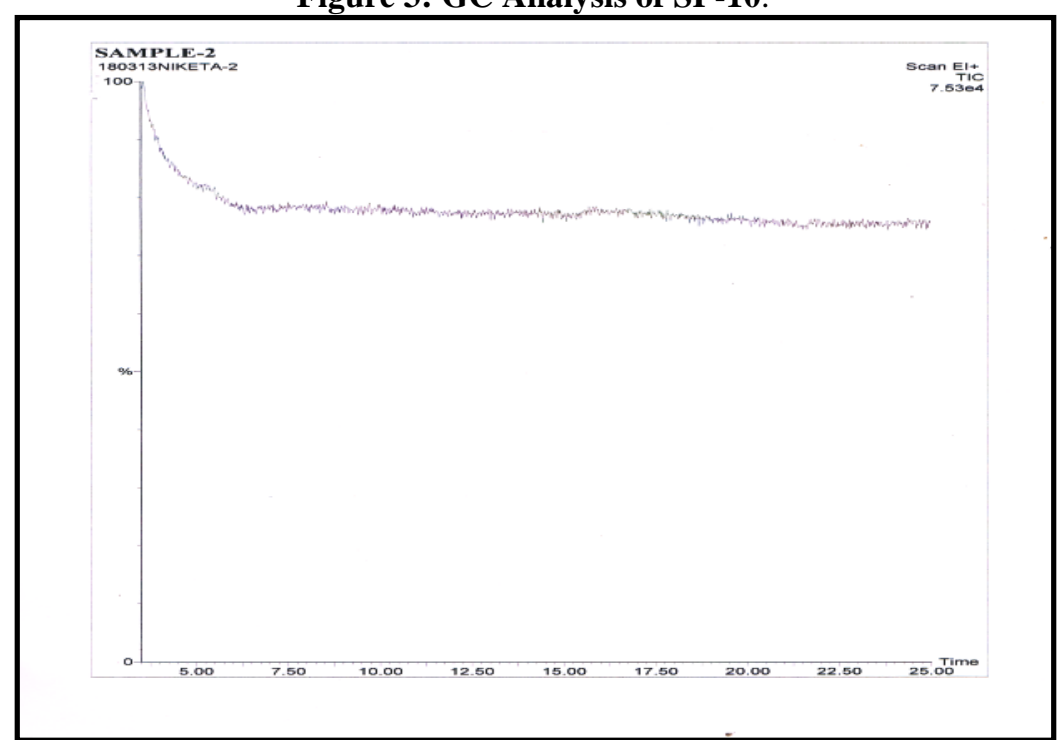

Figure 4: GC Analysis of SP-16.

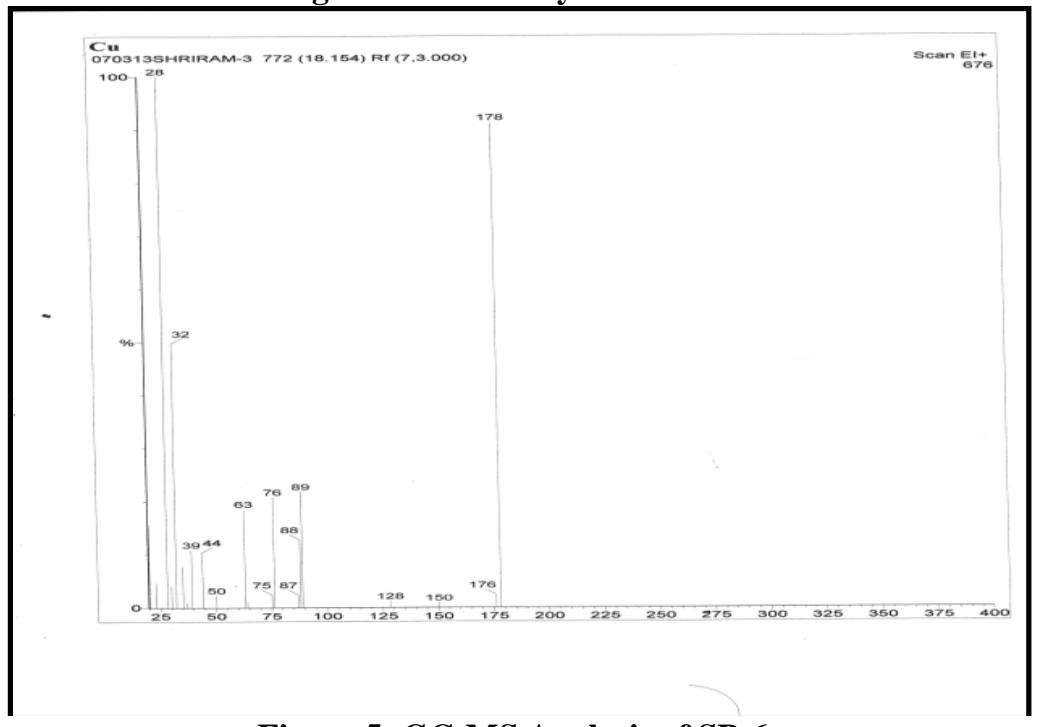

Figure 5: GC-MS Analysis of SP-6. 


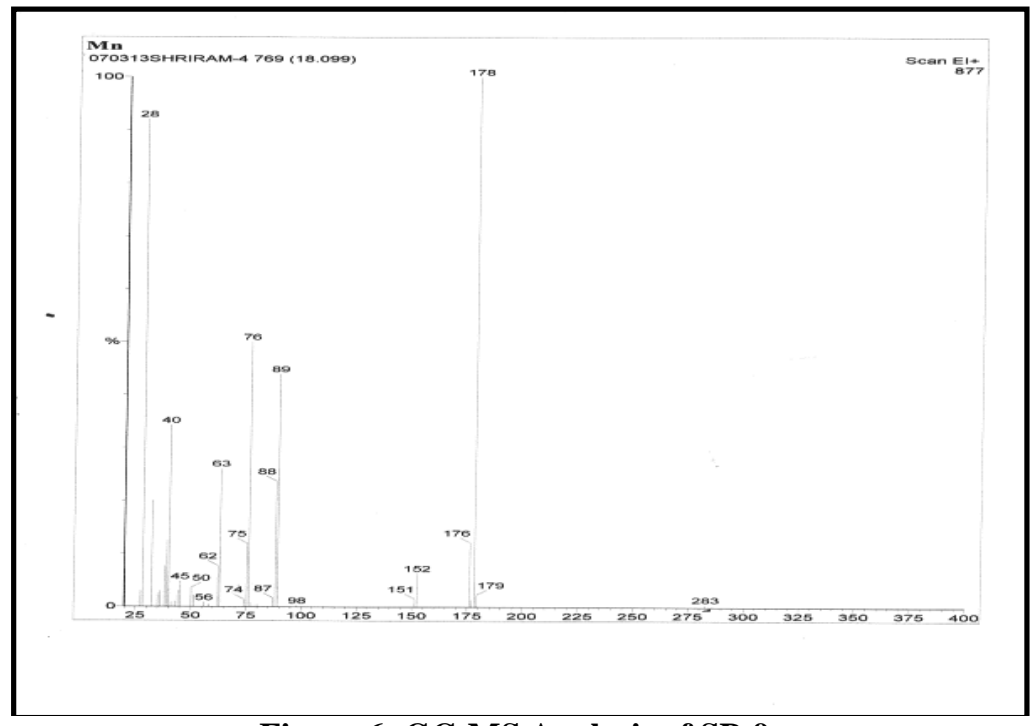

\section{Molecular Characterization of fungal genomic DNA}

Figure 6: GC-MS Analysis of SP-9.

$18 \mathrm{~S}$ rDNA sequence of 6 isolates of fungi were about $650 \mathrm{bp}$ long. Homology search of sequences retrieved from fungal cultures showed a higher sequence similarity to a known sequence and found some closely related strain of fungi. Sequences were submitted to GenBank. Accession numbers are listed in Table 3. Phylogenetic analysis revealed some interesting results. Isolated fungus Penicillium sp. (KF284157) andPenicilliumdecumbens (KF284158) having efficiency to degrade anthracene are closely related in sequences to Aspergillusoryzae (EU583496) and Pestalotiopsismaculans (EU725821) having capacity to degrade nicotine and textile effluent respectively. Trichoderma sp. (KF284161) having efficiency to degrade 100\% anthracene is closely similar to Phanerochaete sp. (JN253599) having capacity to degrade PAHs.

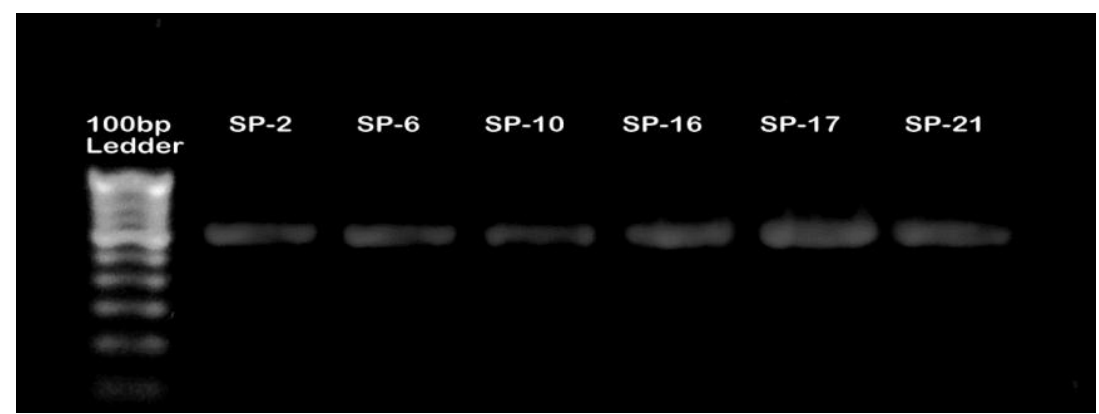

Figure 7: Amplified PCR Products on 1\% Agarose gel.

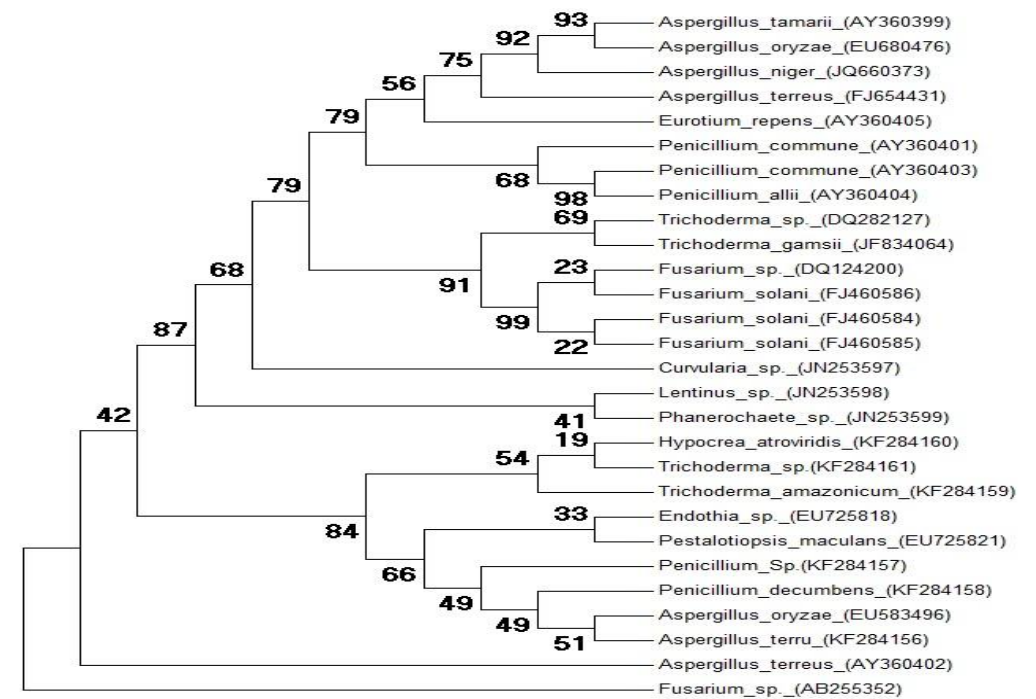

Figure 8: Neighbour-Joining Phylogenetic Tree based on 18s rDNA Sequence of Isolated Fungi Align with the Sequence of Known Xenobiotic Degrading Fungi. 
Table 3: Accession Number Provided to the Sequences.

\begin{tabular}{ccc}
\hline Isolate No. & Accession Number & Name of the organism \\
\hline SP-1 & KF284156 & Aspergillusterreus \\
\hline SP-10 & KF284157 & Penicillium Sp. \\
\hline SP-6 & KF284158 & Penicilliumdecumbens \\
\hline SP-17 & KF284159 & Trichodermaamazonicum \\
\hline SP-21 & KF284160 & Hypocreaatroviridis \\
\hline SP-16 & KF284161 & Trichoderma Sp. \\
\hline
\end{tabular}

\section{Conclusion}

Our isolates of Penicillium decumbence (KF284158) and Hypocreaatroviridis (KF284160) were highly efficient in removal of hexavalent chromium. Similarly two other isolates, Penicillium sp. (KF284157) and Trichoderma sp. (KF284161) have remarkable capacity to degrade anthracene which are also proficient for $\mathrm{Cr}$ removal. It can be concluded that the latter two isolates are more significant in accomplishing both the purpose i.e. removal of hexavalent chromium and degradation of anthracene and can be used at industrial level.

\section{Acknowledgement}

Authors are very thankful to the CharutarVidyaMandal (CVM) and SICART, VallabhVidyanagar, for providing necessary instrumentation facility during research work.

\section{References}

[1]. R. Singh and P. Singh, Pollution in Abu drainage -a preliminary report, Current advances in Plant Science, 13, 2000, 43-45.

[2]. M. X. Gavrilescu, Removal of heavy metals from the environment by biosorption. Engineering in Life Science,4, 2002, $219-232$.

[3]. M. Iqbal and R. G. J. Edyvean, Biosorption of lead, copper and zinc ions on loofa sponge-immobilized biomass of Chlorella sorokiniana: characterization studies, Journal of Harazardous Materials, 108, 2004, 85-94

[4]. T. Ankar and S. Tunali, Biosorption performance of Botrytis cinereafungal byproducts for removal of Cd (II) and Cu (II) ions from aqueous solutions, Mineral engineering, 18, 2005, 1099-1109.

[5]. K.Anju, P. Binal, K. Prashantand S. Hiren, Isolation and characterization of heavy metal resistant bacteria from industrial effluent, Amala khadi Ankleshwar, Gujarat, International journal of Environmental science, 3(5), 2013, 1689-1699.

[6]. P. Baldrian and J. Gabriel, Intraspecific variability in growth response to cadmium of the wood-rotting fungus Piptoporusbetulinus, Mycologia, 94, 2002, 428-436.

[7]. G. M. Gadd, Metals and microorganisms - a problem of definition. FEMS Microbiology Letters, 100, 1992, $197-203$.

[8]. A. D. Dayan and A. J. Paine, Mechanisms of chromium toxicity, carcinogenicity and allergenicity: review of the literature from 1985 to 2000, Human \& Experimental Toxicology, 20, 2001, 439-451.

[9]. K. L. White, An overview of immunotoxicology and carcinogenic polycyclic aromatic hydrocarbons, Environmental Carcinogenesis \& Ecotoxicology Review, 1986, 163-202.

[10]. R. Palhmann and O. Pelkonen, Mutagenicity studies of different polycyclic aromatic hydrocarbons: the significance of enzymatic factors and molecular structures, Carcinogenesis, 8, 1987, 773-778.

[11]. K. Fujikawa, L. L. Fort, K. Samejima and Y. Sakamoto, Genotoxic potency in Drosophila melanogaster of selected aromatic amines and polycyclic aromatic hydrocarbons as assayed in the DNA repair test, Mutatation Research, 290, 1993, $175-182$.

[12]. H. Sing, Mycoremediation (John Wiley \& Sons, Inc., Hoboken, New Jersey, USA, 2006).

[13]. Ahmad, S. Zafar and F. Ahamd, Heavy Metal Biosorption potential of Aspergillus sp. And Rhizopus sp. isolated from Wastewater treated soil, Journal of Applied Science and Environment Management, 9, 2005, 123-126.

[14]. L. Ezzourhi, E. Castro, M. Moya, F. Espinola and K. Lairini, Heavy metal tolerance of filamentous fungi isolated from polluted sites in Tangier, Morocco, African Journal of Microbiology Research, 3, 2009, 035-048.

[15]. J. Q. Yang, H. Wang, Q. Luo, Q. Wang and T. J. Wu, Biosorption behavior of heavy metals in bioleaching process of MSWI fly ash byAspergillusniger, Biochemical Engineering Journal, 46(3), 2009, 294-299.

[16]. N. L. Iskandar, N. A. I. Mohdzainudin and S. G. Tan, Tolerance and biosorption of copper (Cu) and lead (Pb) by filamentous fungi isolated from a freshwater ecosystem, Journal of Environmental Sciences, 23, 2011, 824-830.

[17]. A. J. Munzoa, E. Ruiz, H. Abriouel, L. Ezzouhri et al, Heavy metal tolerance of microorganisms isolated from wastewaters: Identification and evaluation of its potential for biosorption, Chemical Engineering Journal, 210, 2012, 325-332.

[18]. M. A. Jackson, D. P. Labeda and L. A. Becker, Isolation for bacteria and fungi for the hydrolysis of phthalate and terephthalate esters, Journal of industrial Microbiology, 16, 1996, 301-304.

[19]. H. Mun-Jung, C. Hyoung-Tae, S. Hong-Gyu, Degradation of Phenanthrene by Trametesversicolor and its Laccase, Journal of Microbiology, 42, 2004, 94-98.

[20]. D. B. Gary, F. Maxime and W. Allan, , Degradation of contrasting pesticides by white rot fungi and its relationship with ligninolytic potential, Journal of FEMS Microbiology Letters, 212, 2002, 59-63.

[21]. M. Y. Arica and G. Bayramoglu, Biosorption from aqueous solutions using free and immobilized biomass of Lentinussajor-caju: preparation and kinetic characterization, Colloids and surface A: Physicochemical and Engineering aspect, $253,2005,203$ - 211.

[22]. D. Park, Y. S. Yun, J. H. Jo and J. M. Park, Mechanism of hexavalent chromium removal by dead fungal biomass of Aspergillusniger, Water Resources, 39, 2005, 533-540.

[23]. X. Han, Y. S. Wong, M. H. Wong and N. F. Y. Tam, Biosorption and bioreduction of Cr (VI) by a microalgae isolate chlorella miniata, Journal of Hazardous Material, 146, 2007, 65-72.

[24]. A. E. Greenberg, J. J. Connors, D. Jenkins and M. A. Frason, Standard Methods for the Examination of Water and Waste-water, 15th ed. 187-19, (American Public Health Association, Washington, D.C, 1981)

[25]. D. W. Cullen and P. R. Hirsch, Simple and rapid method for direct extraction of microbial DNA from soil for PCR, Soil Biology and Biochemistry, 30,1998, 983-993.

[26]. K. Tamura, D. Peterson, N. Peterson, G. Stecher, M. Nei et al, MEGA5: Molecular Evolutionary Genetics Analysis using Maximum Likelihood, Evolutionary Distance, and Maximum Parsimony Methods, Molecular Biology and Evolution, 28, 2011, 2731-2739. 
[27]. V. Kathuria, Informal regulation of pollution in a developing country: evidence from India, Ecological Economics, 63, 2007, 403417.

[28]. G. M. Gadd, Interaction of fungi with toxic metals, New Phytologist, 124, 1993, 25 - 60

[29]. F. Tsubasa, I. Yasuhiro, O. Akane, T. kadzuyo and M. Hiroshi, Cr (VI) reduction from contaminated soils by Aspergillus sp.N2 and Penicillium sp. N3 isolated from chromium deposits, General and Applied Microbiology, 54, 2008, $295-303$.

[30]. S. Zafar, F. Aqil and I. Ahmed, Metal tolerance and biosorption potential of filamentous fungi isolated from metal contaminated agricultural soil,Bioresources Technology, 98, 2007, 2557-2561.

[31]. R. Say, N. Yilmaz and A. Denizli, Removal of Cr (VI) ions from synthetic solutions by the fungus Penicilliumpurpurogenum, Engineering in Life Science, 4, 2004, 276-280.

[32]. B. R. M. Vyas, V. Bakowski, V. Sasek and M. Matucha, Degradation of anthracene by selected white rot fungi, FESM Microbiology Ecology, 14, 1994, 65-70.

[33]. W. Yi-Rui, L. Zhu-Hua and L. L. P. Vrijmoed, Biodegradation of anthracene and benz[a]anthracene by two Fusariumsolani strain isolated from mangrove sediments, Bioresource Technology, 101, 2010, 9666-9672. 